\title{
Extraction of Hydroxyapatite from Bovine and Human Cortical Bone by Thermal Decomposition and Effect of Gamma Radiation: A Comparative Study
}

\begin{abstract}
Hydroxyapatite (HA) was extracted from bovine and human cortical bone by thermal decomposition process and was characterized using several analytical tools, including thermo-gravimetric analysis (TGA), X-ray diffraction analysis (XRD), X-ray fluorescence analysis (XRF), Flourier transformed infrared spectroscopy (FTIR) and scanning electron microscopy (SEM). Removal of organic matter from the bone was confirmed by TGA. XRD data confirmed that $\mathrm{HA}$ was the only crystalline phase when sintered at $950^{\circ} \mathrm{C}$. XRF analysis revealed that calcium and phosphorus were the main components and magnesium, sodium were the minor elements in which some trace elements (iron, potassium and zinc) were also present. FT-IR spectra of HA confirmed the presence of a carbonated group and the similarities to commercial HA. When HA were irradiated at 25kGy, there was no significant change of their properties. In vitro cytotoxicity of the HA powder were also evaluated and the samples showed no cytotoxic effect. These results suggested that HA derived from bovine and human bone by thermal decomposition has the potential to be used in bone tissue engineering.
\end{abstract}

Keywords: Hydroxyapatite; Human bone; Crystallinity; Radiation; Cytotoxicity

\author{
Research Article \\ Volume 8 Issue 3 - 2017 \\ Masud Rana, Naznin Akhtar, Shaifur \\ Rahman, Hossen Mohammad Jamil and \\ Sikder M Asaduzzaman* \\ Institute of Tissue Banking and Biomaterial Research, Atomic \\ Energy Research Establishment, Bangladesh \\ *Corresponding author: Sikder M Asaduzzaman, Institute \\ of Tissue Banking and Biomaterial Research, Atomic Energy \\ Research Establishment, Dhaka 1349, Bangladesh, Tel: \\ +8801726894690; Fax: 88027790034; Email: \\ sikderasad@yahoo.com
}

Received: July 09, 2017 | Published: August 21, 2017

\section{Introduction}

In the recent year, the use of artificial materials in the biomedical application has been increased significantly due to the limited accessibility of natural bone for grafting. When the fracture is occurred, the ability of self-repairing of bone is limited. Small fractures are usually able to heal perfectly, but larger fractures can leave permanent damage [1-2].

For the treatment of bone defect autogenous bone is most desirable, but there are several drawbacks and risks involved in using autogenic bone such as limited harvest due to insufficient donors, post-operative pain, increased blood loss, secondary surgical wounds and risk of thrombosis [3-5]. Allograft bone could overcome the above limitations, but it endures the risk of transmission of infection (e.g. HIV, Hepatitis etc.) [6-8]. another possible alternative of treatment for bone defect is xenogenous bone, which is morphologically and structurally similar to human bone. It is usually derived from bovine origin and easy to obtain, lower cost and available in unlimited supply.

At the material level, bone is composed of organic and inorganic components. The organic part contains mainly collagen and proteins, whereas the inorganic component is mainly hydroxyapatite (HA) with a small percentage of other elements being incorporated in the structure such as carbonate, magnesium and sodium etc [9].

HA is one type of bio-ceramic materials that properties and structure is resemblance with the mineral phase of bone. It is not only a biocompatible, osteoconductive, osteoinductive, nontoxic, non-inflammatory and non-immunogenic agent, but also bioactive and has the ability to form a bond with the surrounding bone tissue after implantation. It has been studied to grow and develop to similar natural bone [10-12].

Different chemically synthesis methods were reported for HA, such as sol-gel [13], wet chemical precipitation [14], hydrothermal method [15], microwave irradiation [16] etc. Synthesized HA does not have adequate biological properties as the natural apatite existing in bones. In this regard, scientists have attempted to produce synthetic HA scaffolds from several natural sources such as coral [17], egg shells [18,19], and bone [20,21].

Sterilization is important to use HA in bone defect. Gamma radiation has been widely used in sterilization application for different materials. The effect of gamma radiation on HA will be good information for application of HA in bone tissue engineering. The purpose of this work to investigated properties and characteristics of gamma radiation on $\mathrm{HA}$ which derived from bovine and human bone via thermal decomposition process.

\section{Materials and Methods}

\section{Material}

Cortical bone (femur, tibia, fibula, humerus, radius and ulna) of adult bovine ( $\sim 2$-3 years old) was procured from local slaughtering house (Bolivadra bazaar, Savar, Dhaka, Bangladesh). Human cortical bone used in this study was a biologically no longer active 
femur, collected from the National Institute of Traumatology and Orthopedic Rehabilitation (NITOR), Dhaka, Bangladesh. All the long bones were cleaned to remove visible adhered impurities and substances such as joint cartilage, ligaments and soft tissues stuck on the bone using bp blade no 22 . Then the bones were cut at the metaphysis using electric band saw (AEW, 250) and the diaphysis of the bones was taken for HA extraction.

\section{Bone preparation}

Human and bovine bone samples were separately boiled in deionized water for about 8 hours for easy removal of the bone marrow and tendons. Then the bones were cut into small pieces $(\sim 10 \mathrm{~mm} \times 5 \mathrm{~mm} \times 5 \mathrm{~mm})$. After that the bone has been deproteinized by boiling in water. The boiled bone samples were dried overnight at $100^{\circ} \mathrm{C}$ in order to avoid soot formation on the surface of the material during the heating treatment.

\section{Thermal decomposition}

The as received dried bone samples were annealed in an electric furnace (Borel, 1600, Swetzarland), under ambient condition at four different temperatures ranging from 650 to $1250{ }^{\circ} \mathrm{C}$, using a heating rate of $5^{\circ} \mathrm{C} / \mathrm{min}$ with 3 hours holding time consequentially as multi stage sintering. These temperatures were selected after a preliminary thermogravimetric analysis. The sintered product was crashed with mortar \& pestle and sieved with mesh no. 200. To determine the color and weight loss of bone sample at individual stage, samples were sintered at $200-1200{ }^{\circ} \mathrm{C}$ using a heating rate of $5^{\circ} \mathrm{C} / \mathrm{min}$ with 3 hours holding time at 100 ${ }^{\circ} \mathrm{C}$ temperature interval.

\section{Characterization mthods}

For characterization of as-prepared HA, phase purity analysis, particle size determination and microstructural analysis were performed using X-ray diffraction (XRD) and scanning electron microscopy (SEM) subsequently. The phase and crystallinity of HA were evaluated using X-ray diffractometer (X'Pert PRO $\mathrm{PW} 3040), \mathrm{Cu}-\mathrm{K} \alpha$ radiation and over a range $2 \theta$ from $10^{\circ}$ to $70^{\circ}$ angle, step size $0.02 / \mathrm{s}$, with $40 \mathrm{kV}$ voltages and $30 \mathrm{~mA}$ current. The XRD pattern were analyzed and compared with "X"pert high score and "X'Pert plus" software (Xpert Highscore" File No. 01086-0740) to identify the phase. Mass loss pattern during heating were studied by using a TGA analyzer (TGA analyzer, Model Q600, USA). The thermo-gravimetric analysis of the bone samples during heating were recorded from $30^{\circ} \mathrm{C}$ to $800{ }^{\circ} \mathrm{C}$ at a heating rate of $10^{\circ} \mathrm{C} / \mathrm{min}$ in a continuous flow of nitrogen. The stretching frequencies of samples were examined by FTIR analysis (FTIR 8400S, Shimadzu spectrophotometer, Japan) in the range 4000$40{ }^{\circ} \mathrm{Cm}^{-1}$. Morphology of HA crystals was obtained by Scanning electron microscopy (JSM 6490LA, Jeol, Japan). A shimadzu XRF-1800, X-ray fluorescence spectrometer was used to obtain elemental chemical composition of the extracted powder. In order to prepare samples for XRF analysis, the powder was poured into a special die and compacted in a pressing machine with $40 \mathrm{kN}$ load to prepare a disk shaped specimen $15 \mathrm{~mm}$ in diameter and 2 $\mathrm{mm}$ in thickness.

\section{In vitro cytotoxicity study}

The brine shrimp lethality bioassay method was used to predict the cytotoxic activity of the desired sample. It is also a primary toxicity screening technique used as an initial screening of bioactive compounds. The brine shrimp, Artemia salina, was used as a convenient monitor for the screening. The eggs of the brine shrimp, hatched in artificial seawater $(3.8 \% \mathrm{NaCl}$ in water) and $\mathrm{pH}$ was adjusted at 8.5 using $0.1 \mathrm{~N} \mathrm{NaOH}$ under constant aeration for $48 \mathrm{hr}$ to mature shrimp called nauplii. After hatching, active nauplii were collected from brighter portion of the hatching chamber and used for the assay. HA powder was dissolved in artificial seawater at $0.25,0.50$ and $0.75 \mathrm{mg} / \mathrm{mL}$ concentration and was taken in Petri plates where the active nauplii were inoculated. After overnight incubation, the nauplii were counted. At the same time, $0.5 \mathrm{mg} / \mathrm{mL}$ of vincristine sulfate was used to as a positive control.

\section{Results and Discussion}

\section{Calcinations temperature determination}

The TGA result figure- 01 shows that the TGA curve reaches balance at $600{ }^{\circ} \mathrm{C}$. It indicates that the organic substances in human and bovine bone removed fully. Based on TGA result, 650 ${ }^{\circ} \mathrm{C}$ was chosen as the minimum temperature to calcine the sample as multi stage sintering.

\section{General observation}

In this study, HA was extracted from bovine and human cortical bone by thermal decomposition processes. In this process, bones were multi stage calcined at different temperature sequentially. In this process $62.71 \%$ and $59.32 \%$ of HA was extracted from bovine and human bone respectively (Table 1).

During calcination at different temperature, the percentage of weight loss and color change of bovine and human bones are shown in table-01. After calcination at different temperatures, the colors of the bone were changed due to removal of organic portion. The color of the raw bovine bone was observed as yellowish and yellowish white for bovine and human respectively, which consequently altered into brownish, black, light black, dark ash and gray for bovine bone and off white, black, charcoal, dark ash and gray for human bone at $200^{\circ} \mathrm{C}, 300{ }^{\circ} \mathrm{C}, 400^{\circ} \mathrm{C}, 500$ and $600^{\circ} \mathrm{C}$ temperatures respectively. The color of the bovine and human bone turned into white with further increase in the temperature. The different colors observed below $700^{\circ} \mathrm{C}$ revealed the association of the organic matrix within the bone.

\section{Thermo-gravimetric analysis}

The removal of the organic portion from bovine bone and human bone confirmed by TGA analysis and the results are shown in Figure 1.

In the TGA curves, two inflection points were observed in the bovine bone and human bone at $100.0^{\circ} \mathrm{C}$ and $500{ }^{\circ} \mathrm{C}$ which corresponds to removal of the water and organic matter. No significant weight loss was observed between $600{ }^{\circ} \mathrm{C}$ and 800 
${ }^{\circ} \mathrm{C}$, indicating the complete removal of organic materials such as collagen, chondroitin sulfate, keratin sulfate, and lipids below 600 ${ }^{\circ} \mathrm{C}$ in both bovine and human bone.

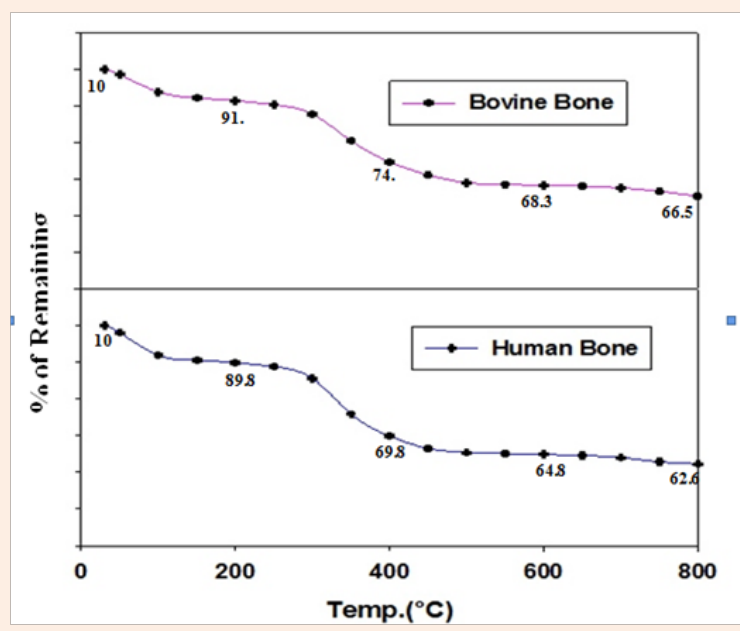

Figure 1: TGA analysis of bovine and human bone.

\section{XRD Analysis}

The phase and purity of derived HA crystals were confirmed with XRD analysis. Figure- 2 shows the XRD patterns of the bovine and human bone produced after annealing at (a) $650{ }^{\circ} \mathrm{C}$, (b) 950 ${ }^{\circ} \mathrm{C}$, (c) $1050{ }^{\circ} \mathrm{C}$ and (d) $1250^{\circ} \mathrm{C}$ and the XRD data of the $950{ }^{\circ} \mathrm{C}$ are tabulated in Table 2 with standard HA ("Xpert Highscore" File No. 01-086-0740) (Figure 2).

These diffraction patterns show a gradual increase in the degree of sharpness of peaks with increasing heat treatment temperature, indicating the extent of crystallinity of the HA produced at various temperatures. Further, it also shows the influence of preparing temperature to HA crystal size. The main peak of HA crystals lead to broader diffraction peaks. With the temperature increasing from 650 to $1250^{\circ} \mathrm{C}$, the HA peaks become sharper and more distinct at $950^{\circ} \mathrm{C}$ treated sample. The sharp and distinct peaks indicated a high degree of crystallinity. It means that less than $950^{\circ} \mathrm{C}$ has no influence to HA crystal size. At the upper temperature HA crystal does not increase continuously with the rising temperature. Further increasing of temperature HA may convert into another phases of calcium apatite.
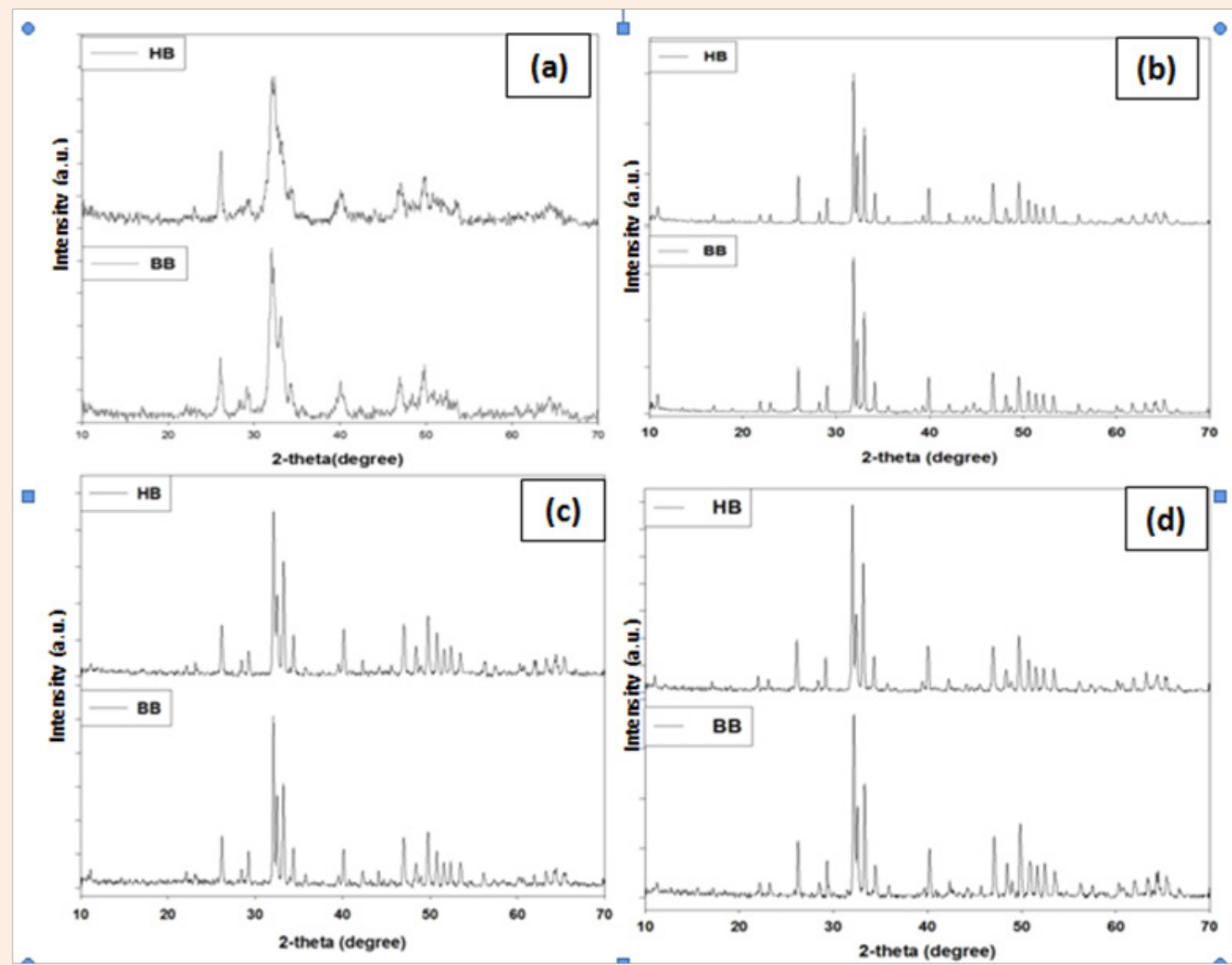

Figure 2: XRD analysis of HA, extraction from bovine bone (bHA) and human bone (hHA) through annealing. (a) $650^{\circ} \mathrm{C}$ (b) $950^{\circ} \mathrm{C}$ (c) $1050^{\circ} \mathrm{C}$ (d) $1250^{\circ} \mathrm{C}$ 
Table 1: Residues and color of calcined bovine and human bone.

\begin{tabular}{|c|c|c|c|c|c|}
\hline \multirow{2}{*}{ S. No. } & \multirow{2}{*}{ Temperature $\left({ }^{\circ} \mathrm{C}\right)$} & \multicolumn{2}{|c|}{$\%$ of weight loss } & \multicolumn{2}{|c|}{ Color } \\
\hline & & Bovine Bone & Human Bone & Bovine Bone & Human Bone \\
\hline 1 & Raw Bone & $\mathrm{n} / \mathrm{a}$ & $\mathrm{n} / \mathrm{a}$ & Yellowish & Yellowish white \\
\hline 2 & 200 & 4.28 & 4.18 & Brownish & Off white \\
\hline 3 & 300 & 22.63 & 26.37 & Black & Black \\
\hline 4 & 400 & 23.37 & 27.43 & Light black & Charcoal \\
\hline 5 & 500 & 26.47 & 30.08 & Dark ash & Dark ash \\
\hline 6 & 600 & 27.01 & 31.22 & Gray & Gray \\
\hline 7 & 700 & 30.66 & 33.99 & White & White \\
\hline 8 & 800 & 31.27 & 34.32 & White & White \\
\hline 9 & 900 & 32.05 & 34.58 & White & White \\
\hline 10 & 1000 & 32.89 & 34.79 & White & White \\
\hline 11 & 1100 & 34.64 & 37.13 & Snow white & Snow white \\
\hline 12 & 1200 & 37.81 & 40.17 & Crystal white & Crystal white \\
\hline
\end{tabular}

Table 2: Degree of crystallinity for HA extracted from bovine bone (bHA) and human bone (hHA) with different calcination temperature.

\begin{tabular}{|c|c|c|c|c|c|}
\hline \multirow{2}{*}{ No } & \multirow{2}{*}{ Temperature $\left({ }^{\circ} \mathrm{C}\right)$} & \multicolumn{2}{|c|}{ Degree of Crystallinity (\%) } & \multicolumn{2}{|c|}{ Degree of Crystallinity } \\
\hline & & bHA & hHA & bHA & hHA \\
\hline 1 & 650 & Not Separated Peak & Not Separated Peak & Amorf & Amorf \\
\hline 2 & 950 & 98.92 & 99.13 & High & High \\
\hline 3 & 1050 & 98.70 & 99.06 & High & High \\
\hline 4 & 1250 & 98.51 & 98.82 & High & High \\
\hline
\end{tabular}

The different prominent XRD peak position and d-spacing and compared with the standard HA ("Xpert Highscore" File No.

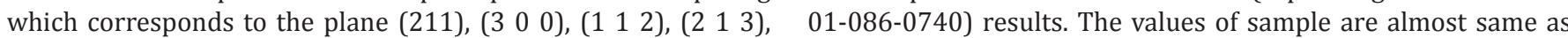
$\left(\begin{array}{lll}2 & 2 & 2\end{array}\right)$ and $\left(\begin{array}{lll}2 & 0 & 2\end{array}\right)$ of annealed bone (bHA and hHA) at $950^{\circ} \mathrm{C}$ standard HA value (Supplementary Table 1).

Supplementary Table 1: Position of XRD peaks of HA annealed at $950 \stackrel{\circ}{\circ}$, the results are compared with the standard HA ("Xpert Highscore" File No. 01-086-0740).

\begin{tabular}{|c|c|c|c|c|c|c|}
\hline \multirow{2}{*}{$\begin{array}{l}\text { Miller Indices } \\
\text { (h k l) }\end{array}$} & \multicolumn{3}{|c|}{ d-spacing $\left(A^{0}\right)$} & \multicolumn{3}{|c|}{$2 \theta$} \\
\hline & Standard & bHA & hHA & Standard & bHA & hHA \\
\hline$\left(\begin{array}{lll}2 & 1 & 1\end{array}\right)$ & 2.79695 & 2.79467 & 2.80903 & 31.973 & 32.026 & 31.858 \\
\hline$\left(\begin{array}{lll}3 & 0 & 0\end{array}\right)$ & 2.69969 & 2.70126 & 2.71427 & 33.157 & 33.165 & 33.001 \\
\hline$\left(\begin{array}{lll}1 & 1 & 2\end{array}\right)$ & 2.77146 & 2.76131 & 2.77509 & 32.275 & 32.424 & 32.258 \\
\hline$\left(\begin{array}{lll}2 & 1 & 3\end{array}\right)$ & 1.83574 & 1.83373 & 1.84218 & 49.620 & 49.722 & 49.478 \\
\hline$\left(\begin{array}{lll}2 & 2 & 2\end{array}\right)$ & 1.93385 & 1.93515 & 1.94421 & 46.947 & 46.955 & 46.722 \\
\hline$\left(\begin{array}{lll}2 & 0 & 2\end{array}\right)$ & 2.62219 & 2.61660 & 2.62615 & 34.167 & 34.271 & 34.142 \\
\hline
\end{tabular}

Citation: Rana M, Akhtar N, Rahman S, Jamil HM, Asaduzzaman SM (2017) Extraction of Hydroxyapatite from Bovine and Human Cortical Bone by Thermal Decomposition and Effect of Gamma Radiation: A Comparative Study. Int J Complement Alt Med 8(3): 00263. D0I: 
To obtain a level of perfection information HA crystal formation, was calculated (degree of crystallinity) sing the following equation-

Xc $(\%)=1-(V 112 / 300 /$ I 300)

Where

V112/300 = Valley intensity between peaks 112 and 300

I $300=$ Peak intensity 300

$\mathrm{Xc}$ value is a fraction of crystalline phases that exist in the sample where:

Xc $>70 \%$ usually considered to be a high degree of crystal

$30 \%>$ Xc $>70 \%$ Medium degree of crystal

Xc $<30 \%$ low degree of crystal

By using the formula above then degrees of crystalline of HA could be calculated and tabulated at Table 2 .

XRD analyzes were performed on HA powder from bovine and human bones are calcined with temperature variations between $650-1250{ }^{\circ} \mathrm{C}$ resulting from this research is the HA phase. In this research, it also revealed that, by increasing rate of calcination temperature, the degree of crystallinity is decreased due to conversion of HA into other apatite phases. It is also noted that the crystallinity rate of hHA is more than bHA.

\section{FTIR Analysis}

FTIR spectrum values of HA was extracted from bovine cortical bone (bHA) and human bone (hHA) by annealing at $950^{\circ} \mathrm{C}$ as summarized in Table 3 . The results are compared with commercially synthetic HA (Sigma CAS No.12167-74-7). It shows that, a large number of bands in the spectra $(470,572$, $603,1058,1462,1633,2854,2924,3452,3782 \mathrm{~cm}-1$ ) matches the bands in the commercial HA (cHA) reference spectrum and are in close agreement with reported data on HA [22]. The absorption bands at 3452, $3782 \mathrm{~cm}-1$ in cHA, 3456,3774 cm-1 in bHA and $3456,3773 \mathrm{~cm}-1$ in hHA respectively correspond to the stretching and vibration of the lattice $\mathrm{OH}$ - ions, while the bands of absorbed water are shown at $1633,2854,2924 \mathrm{~cm}-1 ; 1633,2860$, $2927 \mathrm{~cm}-1$ and 1634, $2928 \mathrm{~cm}-1$. The characteristic bands for C032- were assigned at $1411,146^{\circ} \mathrm{Cm}-1$ for bHA and 1462,1414 cm-1 for hHA correspondingly; no peak were presented in cHA. Manalu et al. [] reported that the stretching band 3420-3570 cm-1 originate by hydroxyl group [23]. Carbonate ions are a common impurity in both synthetic and natural HA [24]. The characteristic bands for P043- appeared at 470 and $474 \mathrm{~cm}-1$ for the $v 1$ mode in cHA and bHA sequentially. The signal became clearly as the hydration processing. The observation of the $v 3$ symmetric P-O stretching vibration at 1058 and $1051 \mathrm{~cm}-1$ for cHA and bHA as a distinguishable peak, together with the bands $572 / 603 \mathrm{~cm}-1$ \& $570 / 603 \mathrm{~cm}-1$ corresponding to $v 4$ bending vibration indicates.

Table 3: Peaks of infrared spectra assigned to commercial HA (cHA) and HA derived from bovine bone (bHA) and human bone (hHA).

\begin{tabular}{|c|c|c|c|c|}
\hline \multirow{2}{*}{$\begin{array}{c}\text { Name of the Chemical } \\
\text { Group }\end{array}$} & \multicolumn{3}{|c|}{ Absorption Band Frequency (cm ${ }^{-1}$ ) } & \multirow{2}{*}{ Reference } \\
\cline { 2 - 5 } & cHA & bHA & hHA & [25-26] \\
\hline $\mathrm{PO}_{4}{ }^{3-}$ band V1 & 471 & 474 & 474 & {$[25-26]$} \\
\hline $\mathrm{PO}_{4}{ }^{3}$-band V3 & 1059 & 1051 & 1051 & {$[25-27]$} \\
\hline $\mathrm{PO}_{4}{ }^{3-}$ band V4 & 573,604 & 571,604 & 569,604 & {$[25,28-29]$} \\
\hline $\mathrm{CO}_{3}{ }^{2-}$ & & 1460,1411 & 1462,1414 & {$[26,28]$} \\
\hline Absorbed $\mathrm{H}_{2} \mathrm{O}$ & $1634,2855,2924$ & $1634,2860,2928$ & 1634,2928 & {$[25-27]$} \\
\hline OH structural & 3453,3782 & 3456,3775 & 3456,3773 & \\
\hline
\end{tabular}

Different types of chemical bonds which are present in various components of bone at given infrared absorption bands. Changes in the environment of molecules cause shifts in the intensities and positions of their corresponding absorption bands. The bands associated with the amide groups of proteins $(1250 \mathrm{~cm}-1,1560$ $\mathrm{cm}-1$ and $1650 \mathrm{~cm}-1$ ) which are observed on the spectrum of bone do not exist on the FTIR spectrum of bone ash prepared in this investigation. On the other hand, the bands for phosphate and carbonate groups in bone ash occur at the same wave numbers as those reported for bone [30]. On the other hand, it's the same result as shown in the sample from commercial HA powders. The FTIR spectrum of the sample which was annealed at $950^{\circ} \mathrm{C}$ (Figure 3) is in good agreement with the spectra reported by Markovic et al. [31] for a HA-synthetic reference material [31]. It is also divulged that there are not any significant difference of commercial HA and extracted HA from bovine and human bone.



Figure 3: FTIR results of - commercial $\mathrm{HA}(\mathrm{cHA})$, bovine bone $\mathrm{HA}$ (bHA) and human bone (hHA). 


\section{XRF Analysis}

The results of XRF analysis of the bovine and human HA are presented in table-4. Also, the chemical composition of this material in oxide form is shown in table-5. As seen, calcium and phosphorous are the main components. Also, magnesium and sodium as minor elements and some traces of iron, potassium and zinc are also present. As seen in Table- 6 , the concentrations of $\mathrm{CaO}$ and $\mathrm{P} 2 \mathrm{O} 5$ are 56.0 wt. \% and 41.6 wt. \% in bHA and 57.2 wt. $\%$ and 40.4 wt. $\%$ in hHA respectively. The elemental chemical analysis of natural hydroxyapatite extracted from bovine corticle bone ash has also been reported by Bahrololoom et al. [] and their investigation resulted in identifying numerous elements [32].

Table 4: Elemental composition (XRF analysis) of the HA from bovine bone (bHA) and human bone (hHA), heat treated at $950{ }^{\circ} \mathrm{C}$.

\begin{tabular}{|c|c|c|}
\hline \multirow{2}{*}{ Elements } & \multicolumn{2}{|c|}{ Concentration (wt \%) } \\
\cline { 2 - 3 } & bHA & hHA \\
\hline $\mathrm{Ca}$ & 71.6864 & 72.5675 \\
\hline $\mathrm{P}$ & 26.0458 & 25.1821 \\
\hline $\mathrm{Na}$ & 1.1209 & 1.3040 \\
\hline $\mathrm{Mg}$ & 1.0313 & 0.8123 \\
\hline $\mathrm{Fe}$ & 0.0479 & 0.0615 \\
\hline $\mathrm{K}$ & 0.0385 & 0.0454 \\
\hline $\mathrm{Zn}$ & 0.0291 & 0.0272 \\
\hline
\end{tabular}

This multitude of elements is not surprising to the well accepted since ion exchange can take place in the apatite component of bone. The ionic components of hydroxyapatite, i.e. $\mathrm{Ca} 2+, \mathrm{OH}-$ and P043-can readily be exchanged by other ions. It is obvious that the composition of the trace elements varies considerably in bone depending on some biological factors such as breeding, nutrition etc [22] (Table 5).
Table 5: Composition of the HA from bovine bone (bHA) and human bone (hHA), heat treated at $950^{\circ} \mathrm{C}$, in oxide form.

\begin{tabular}{|c|c|c|}
\hline \multirow{2}{*}{ Elements } & \multicolumn{2}{|c|}{ Concentration (wt\%) } \\
\cline { 2 - 3 } & bHA & hHA \\
\hline $\mathrm{CaO}$ & 55.9647 & 57.1773 \\
\hline $\mathrm{P}_{2} \mathrm{O}_{5}$ & 41.5762 & 40.4299 \\
\hline $\mathrm{MgO}$ & 1.2572 & 0.9925 \\
\hline $\mathrm{Na}_{2} \mathrm{O}$ & 1.1261 & 1.3136 \\
\hline $\mathrm{Fe} 2 \mathrm{O} 3$ & 0.0313 & 0.0407 \\
\hline $\mathrm{K}_{2} \mathrm{O}$ & 0.0280 & 0.0260 \\
\hline $\mathrm{ZnO}$ & 0.0165 & 0.0200 \\
\hline
\end{tabular}

The chemical compositions of natural hydroxyapatite extracted from bovine bone ash were compared with each other in the study of Bahrololoom et al. [32]. They found that the calcium, phosphorus and magnesium contents of natural hydroxyapatite extracted from bovine bone were $\mathrm{CaO}: 53.7$ wt.\%, P205 : 42.7 wt.\%, MgO : 1.77 wt.\% and Na20: 1.71 wt.\%. It can be seen that the results of Table 2 are in good agreement with these results. The concentration of magnesium and sodium determined by XRF analysis of the study made here was found difference, might be due to the type of bovine bone which was used here as the starting material for producing HA. The bovine bones were purchased from the local slaughter house and there was no information about the breed and exact age of the cattle from which the bones were supplied. Breed and age of the animal can be influential parameters determining the composition of the hydroxyapatite in their calcified tissues. There is also a discrepancy of magnesium content in two different types of bone (human and bovine) due to mineral contents are different in human and animal.

Table 6: Peaks of infrared spectra assigned to commercial HA (cHA) and irradiated HA derived from Bovine bone (bHA/R) and Human bone (hHA/R).

\begin{tabular}{|c|c|c|c|}
\hline \multirow{2}{*}{ Name of the Chemical Group } & \multicolumn{3}{|c|}{ Absorption Band Frequency $\left(\mathbf{c m}^{-1}\right)$} \\
\cline { 2 - 4 } & cHA & bHA/R & hHA/R \\
\hline $\mathrm{PO}_{4}{ }^{3-}$ band V1 & 471 & 474 & 474 \\
\hline $\mathrm{PO}_{4}{ }^{3}$-band V3 & 1059 & 1051 & 571,604 \\
\hline $\mathrm{PO}_{4}{ }^{3-}$ band V4 & 573,604 & 571,604 & 1462,1414 \\
\hline $\mathrm{CO}_{3}{ }^{2-}$ & & 1464,1411 & $1636,2860,2928$ \\
\hline Absorbed $\mathrm{H}_{2} \mathrm{O}$ & $1634,2855,2924$ & 1632,2930 & 3458,3780 \\
\hline OH structural & 3453,3782 & 3460,3780 & \\
\hline
\end{tabular}

\section{SEM Analysis}

The surface morphology and crystal size of the extracted HA were determined under SEM analysis. The Scanning electron microscopy (SEM) micrograph of the samples obtained from bovine bone and human at $650-1250^{\circ} \mathrm{C}$ is shown in Figure- 04 After annealing of bovine and human bone at $950^{\circ} \mathrm{C}$, the particle sizes of HA were 195.5-339.8 $\mathrm{nm}$ and 304.80-525.21 $\mathrm{nm}$ sequentially. The average particle size of HA in bHA and hHA were $255.28 \pm 63 \mathrm{~nm}$ and $381.26 \pm 71.01 \mathrm{~nm}$ respectively. When the samples were sintered at $1050^{\circ} \mathrm{C}$ and $1250^{\circ} \mathrm{C}$, the particle sizes of bHA were $315.2-379.9 \mathrm{~nm}$ and $234.9 \mathrm{~nm}-2.084 \mu \mathrm{m}$ in diameter, respectively. On the other hand, at the high temperature the particle of hHA were not measured due to the conjugated each 
other. SEM micrograph of the powder shows that, the particles had irregular shapes, including small spheres, agglomerated together in some parts. It is may be happened due to the inter link up of HA particle each another (Figure 4).

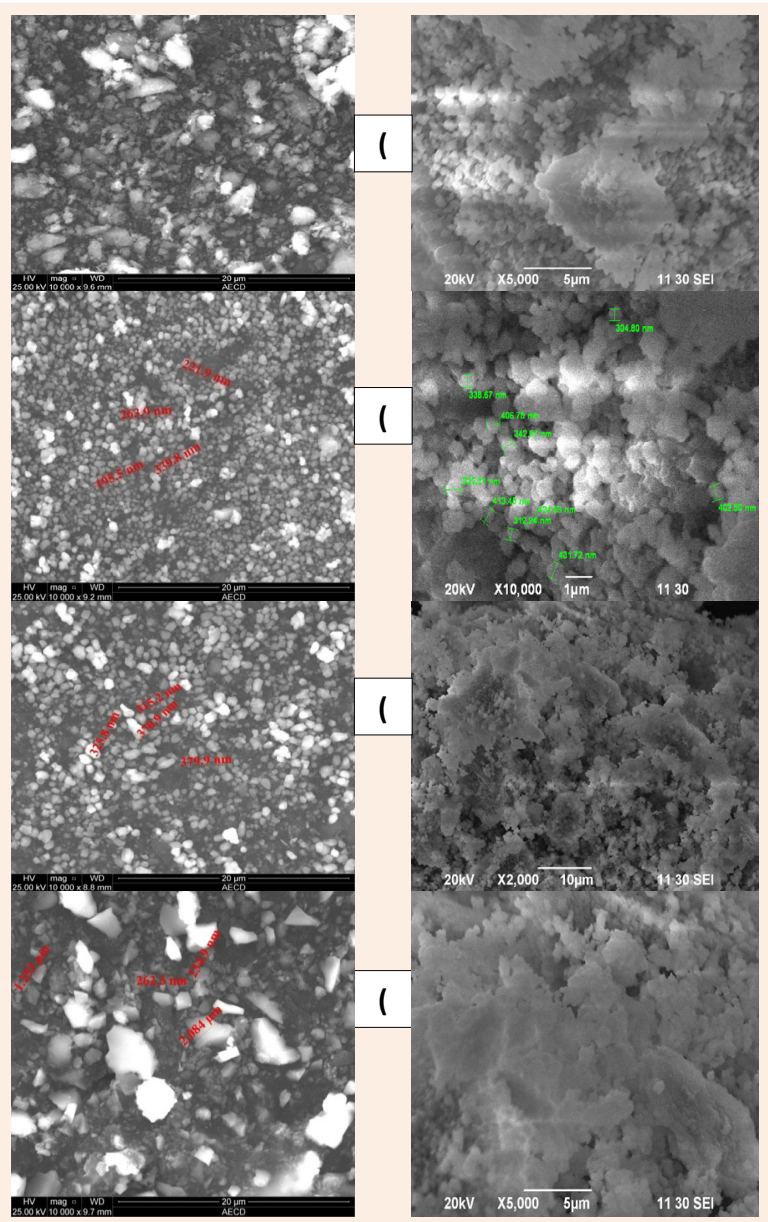

Figure 4: SEM Image of bovine bone and human bone sintered at (a) $650^{\circ} \mathrm{C}$ (b) $950^{\circ} \mathrm{C}$ (c) $1050^{\circ} \mathrm{C}$ (d) $1250^{\circ} \mathrm{C}$.

Accordingly, the morphology of the HA produced from bovine and human bone in the present study also might be influenced by age and nutrition of that particular animal from which the bone for this study was obtained. For the production of HA among the bones of different animals (chicken, pig, sheep and bovine), bovine bone had yielded the highest amount of HA, after burning was chosen as the best starting natural source to get HA. Unfortunately, there was no control on the age and nutrition of the bovine from which the bone was obtained. Thus, further study is necessary to find out at the influence of these biological factors on the morphology of HA.

\section{Effect of Radiation on HA derived from bovine and human bone}

To see the effect of radiation in the extracted HA from bovine and human bone, HA were radiated at $25 \mathrm{kGy}$ and analyzed it. The result was revealed that there were not any significant changed between initial and irradiated samples. The XRD and FTIR results of samples are illustrated below.

XRD analysis: Figure 5 shows the XRD patterns of the HA extracted from bovine and human bone and radiated at $25 \mathrm{kGy}$. From the figure it has been shown that there are not any significant differences between the radiated and irradiated HA. Though, there is some alteration of their value, but is not represent any phase change of calcium apatite from HA.


Figure 5: XRD results of without radiated and irradiated bovine and human bone derived HA - (a) bHA \& bHA/R and (b) hHA \& hHA/R.

It represents the different prominent XRD peak position and d-spacing which corresponds to the plane (211), ( 300 ), (1 112$),(2$ 13 ), ( $\left.\begin{array}{lll}2 & 2 & 2\end{array}\right)$ and ( $\left.\begin{array}{lll}2 & 0 & 2\end{array}\right)$ of non-radiated and radiated HA (bHA and hHA) and also compared with the standard HA ("Xpert Highscore" File No. 01-086-0740) results. The values of sample are almost same as standard HA value (Supplementary Tables 2 \& 3).

FTIR analysis: Table 6 shows that, a large number of bands in the spectra $(474,571,604,1051,1411,1464,1632,2930,3460,3780$ $\mathrm{cm}-1$ ) of radiated bovine HA (bHA/R) and the spectra $(474,571$, $604,1051,1411,1462,1636,2860,2928,3458,3780 \mathrm{~cm}-1)$ of irradiated human HA (hHA/R) are nearly similar to commercial HA (cHA). It is also illustrated that, there are not any significant changed within the different groups of HA, before and after radiation (Figure 6).
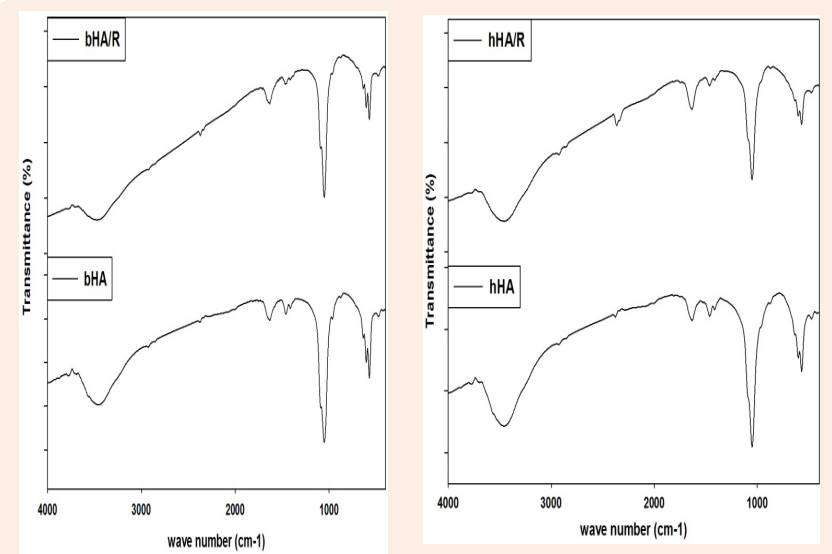

Figure 6: FTIR results of radiated and without irradiated bovine (bHA \& bHA/R) and human bone (hHA \& hHA/R) derived HA. 
So radiation will be a good sterilization process of HA to use it maxillofacial filler and other biomedical application (Table 6)

\section{In vitro cytotoxicity test}

Brine Shrimp Lethality Bioassay method was used for cytotoxic effect of the radiated bHA and hHA powder. Powder was dispersed in artificial sea water in which nauplii were inoculated. The number of death of nauplii was not found to change the concentration of the HA powder (Table 7). So, the result found in present study suggesting that there are not any cytotoxic effect of the extracted HA from bovine and human bone.

Table 7: In-vitro cytotoxicity effect of bovine bone derived HA (bHA) and human bone derived HA (hHA).

\begin{tabular}{|c|c|c|c|c|}
\hline Sample No. & Sample Name & Dose $(\mathrm{mg} / \mathrm{mL})$ & $\begin{array}{l}\text { No. of Nauplii Present After } \\
\text { Incubation }\end{array}$ & Mortality (\%) \\
\hline 1 & Positive control (vincristine sulfate) & 0.5 & 0 & 100 \\
\hline 2 & Negative control (artificial sea water) & - & 10 & 0 \\
\hline 3 & \multirow{3}{*}{ bHA } & 0.25 & 10 & 0 \\
\hline 4 & & 0.50 & 10 & 0 \\
\hline 5 & & 0.75 & 10 & 0 \\
\hline 6 & \multirow{3}{*}{ hHA } & 0.25 & 10 & 0 \\
\hline 7 & & 0.50 & 10 & 0 \\
\hline 8 & & 0.75 & 10 & 0 \\
\hline
\end{tabular}

Supplementary Table 2: Position of XRD peaks of non-radiated and radiated bovine derived HA (bHA \& bHA/R), the results are compared with the standard HA ("Xpert Highscore" File No. 01-086-0740).

\begin{tabular}{|c|c|c|c|c|c|c|}
\hline \multirow{2}{*}{ Miller Indices (h k l) } & \multicolumn{3}{|c|}{ d-spacing $\left(A^{0}\right)$} & \multicolumn{3}{|c|}{$2 \theta$} \\
\hline & Standard & bHA & bHA $/$ R & Standard & bHA & bHA/R \\
\hline$\left(\begin{array}{llll}2 & 1 & 1\end{array}\right)$ & 2.79695 & 2.79467 & 2.80870 & 31.973 & 32.026 & 31.862 \\
\hline$\left(\begin{array}{lll}3 & 0 & 0\end{array}\right)$ & 2.69969 & 2.70126 & 2.71371 & 33.157 & 33.165 & 33.008 \\
\hline$\left(\begin{array}{lll}1 & 1 & 2\end{array}\right)$ & 2.77146 & 2.76131 & 2.77410 & 32.275 & 32.424 & 32.270 \\
\hline$\left(\begin{array}{lll}2 & 1 & 3\end{array}\right)$ & 1.83574 & 1.83373 & 1.84235 & 49.620 & 49.722 & 49.474 \\
\hline$\left(\begin{array}{lll}2 & 2 & 2\end{array}\right)$ & 1.93385 & 1.93515 & 1.94489 & 46.947 & 46.955 & 46.705 \\
\hline$\left(\begin{array}{lll}2 & 0 & 2\end{array}\right)$ & 2.62219 & 2.61660 & 2.62628 & 34.167 & 34.271 & 34.141 \\
\hline
\end{tabular}

Supplementary Table 3: Position of XRD peaks of non-radiated and radiated human derived HA (hHA \& hHA/R), the results are compared with the standard HA ("Xpert Highscore" File No. 01-086-0740).

\begin{tabular}{|c|c|c|c|c|c|c|}
\hline \multirow{2}{*}{ Miller Indices (h k l) } & \multicolumn{3}{|c|}{ d-spacing $\left(A^{\circ}\right)$} & \multicolumn{3}{|c|}{$2 \theta$} \\
\hline & Standard & hHA & hHA/R & Standard & hHA & hHA/R \\
\hline$\left(\begin{array}{lll}2 & 1 & 1\end{array}\right)$ & 2.79695 & 2.80903 & 2.80539 & 31.973 & 31.858 & 31.901 \\
\hline$\left(\begin{array}{lll}3 & 0 & 0\end{array}\right)$ & 2.69969 & 2.71427 & 2.71143 & 33.157 & 33.001 & 33.037 \\
\hline$\left(\begin{array}{lll}1 & 1 & 2\end{array}\right)$ & 2.77146 & 2.77509 & 2.77155 & 32.275 & 32.258 & 32.301 \\
\hline$\left(\begin{array}{lll}2 & 1 & 3\end{array}\right)$ & 1.83574 & 1.84218 & 1.84171 & 49.620 & 49.478 & 49.492 \\
\hline$\left(\begin{array}{lll}2 & 2 & 2\end{array}\right)$ & 1.93385 & 1.94421 & 1.94363 & 46.947 & 46.722 & 46.737 \\
\hline$\left(\begin{array}{lll}2 & 0 & 2\end{array}\right)$ & 2.62219 & 2.62615 & 2.62431 & 34.167 & 34.142 & 34.167 \\
\hline
\end{tabular}

Citation: Rana M, Akhtar N, Rahman S, Jamil HM, Asaduzzaman SM (2017) Extraction of Hydroxyapatite from Bovine and Human Cortical Bone by Thermal Decomposition and Effect of Gamma Radiation: A Comparative Study. Int J Complement Alt Med 8(3): 00263. D0I: 


\section{Conclusion}

Hydroxyapatite is the most prominent inorganic material for bone tissue engineering application as a filler material in osseous and maxillofacial defect. This study showed that the thermal decomposition with high temperature was effective for preparation of natural HA from bovine and human bones. Based on the result of this study, it is revealed that there was no significant difference between bovine and human bone derived HA. Moreover, radiation do not induce any change in the crystallographic properties of the HA.

Though there is no significant difference in chemical properties of HA derived from bovine and human sources, but there may be different in osteoconductive and osteoinductive properties. To determine biological properties (cell adhesion, osteoconductive, osteoinductive), radiation sterilized HA is now being used as filler material for maxillofacial defect in rabbit model. If the results of ongoing tests are hopeful, this extracted HA will be a very good material for maxillofacial filler.

\section{Acknowledgements}

The authors would like to thank the International Atomic Energy Agency (IAEA) for their support to carry out this work as a part of Coordinated Research Project.

\section{Conflict of Interest}

The authors declare that there is no conflict of interest regarding the publication of this paper.

\section{References}

1. Pilia M, Guda T, Appleford M (2013) Development of composite scaffolds for load-bearing segmental bone defects. Biomed Res Int 2013: 1-15.

2. Dimitriou R, Jones E, McGonagle D, Giannoudis PV (2011) Bone regeneration: current concepts and future directions. BMC Med 9: 66-76.

3. Gomes S, Leonor IB, Mano JF, Reis RL, Kaplan DL (2012) Natural and Genetically Engineered Proteins for Tissue Engineering. Prog Polym Sci 37(1): 1-17.

4. Reichert JC, Wullschleger ME, Cipitria A, Lienau J, Cheng TK, et al. (2011) Custom-made composite scaffolds for segmental defect repair in long bones. Int Orthop 35(8): 1229-1236.

5. Pandit N, Pandit IK, Malik R, Bali D, Jindal S (2012) Autogenous bone block in the treatment of teeth with hopeless prognosis. Contemp Clin Dent 3(4): 437-442.

6. Miculescu F, Ciocan L T, Miculescu M Ernuteanu A (2011) Dig J Nanomater Biostruct 6(1): 225- 233.

7. Greenwald MA, Kuehnert MJ, Fishman JA (2012) Infectious disease transmission during organ and tissue transplantation. Emerg Infect Diseas 18(8): e1.

8. Giedraitis A, Arnoczky SP, Bedi A (2014) Allografts in soft tissue reconstructive procedures: important considerations. Sports Health 6(3): 256-264.

9. Akram M, Ahmed R, Shakir I, Wan Aini Wan Ibrahim, Hussain R
(2014) Extracting hydroxyapatite and its precursors from natural resources. J Mater Sci 49: 1461-1475.

10. Thrivikraman G, Madras G, Basu B (2014) In vitro/In vivo assessment and mechanisms of toxicity of bioceramic materials and its wear particulates. RSC Adv 24: 12763.

11. Fahmy MD, Jazayeri HE, Razavi M, Masri R, Tayebi L (2016) ThreeDimensional Bioprinting Materials with Potential Application in Preprosthetic Surgery. J Prosthodont 25: 310-318.

12. Dhandayuthapani B, Yoshida Y, Maekawa T, Sakthi Kumar D (2011) Polymeric Scaffolds in Tissue Engineering Application: A Review. Int J Polym Sci 2011 Article ID 290602.

13. Agrawal K, Singh G, Puri D, Prakash S (2011) Synthesis and Characterization of Hydroxyapatite Powder by Sol-Gel Method for Biomedical Application. J Min Mat Charac Engg 10(8): 727-734.

14. Gentile P, Wilcock C J, Miller CA, Moorehead R, Hatton PV (2015) Process Optimisation to Control the Physico-Chemical Characteristics of Biomimetic Nanoscale Hydroxyapatites Prepared Using Wet Chemical Precipitation. Materials (Basel) 8(5): 22972310 .

15. Yang Y, Wu Q Wang M, Long J, Mao Z, et al. (2014) Hydrothermal Synthesis of Hydroxyapatite with Different Morphologies: Influence of Supersaturation of the Reaction System. Cryst. Growth Des 14(9): 4864-4871.

16. Kumar GS, Sathish L, Govind R, Girijab E K (2015) Utilization of snail shells to synthesise hydroxyapatite nanorods for orthopedic applications. RSC Adv 5: 39544-39548.

17. Roy DM, Linnehan SK (1974) Hydroxyapatite formed from coral skeletal carbonate by hydrothermal exchange. Nature 247(5438): 220-222.

18. Wua SC, Hsua HC, Hsua SK, Changb YC, Fu Ho W (2016) J Asian Ceram Soc 4(1): 85-90.

19. Sanosh KP, Chu MC, Balakrishnan A, Kim TN, Cho SJ (2009) Utilization of biowaste eggshells to synthesize nanocrystalline hydroxyapatite powders. Mater Lett 63: 2100-2102.

20. Ooi CY, Hamdi M, Ramesh S (2007) Properties of Hydroxyapatite Produced by Annealing of Bovine Bone. Ceram Int 33(7): 11711177.

21. Pramanik S, Ataollahi F, Pingguan-Murphy B, Oshkour AA, Osman NA (2014) In Vitro Study of Surface Modified Poly(ethylene glycol)Impregnated Sintered Bovine Bone Scaffolds on Human Fibroblast Cells. Sci Rep 5: 5843.

22. Joschek S, Nies B, Krotz R, Gofpferich A (2000) Biomaterials 21: 1645-1658.

23. Manalu JL, Soegijono B, Indrani DJ (2015) Characterization of Hydroxyapatite Derived from Bovine Bone. Asian j appl Sci 3(4): 1-8.

24. Haberko K, Bucko M, Brzezinska-Miecznik J, Haberko M, Mozgawa W, et al. (2006) Natural hydroxyapatite-its behaviour during heat treatment. J Eur Ceram Soc 26: 537-542.

25. Raynaud S, Champion E, Bernache-Assollant D, Thomas P (2002) Biomaterials 23(4): 1065-1072.

26. Destainville A, Champion E, Bernache-Assollante D, Laborde E (2003) Synthesis, characterization and thermal behaviour of patite tricalcium phosphate. Mater Chem Phys 80: 269-277. 
27. Han JK, Song HY, Saito F, Lee BT (2006) Synthesis of high purity nano-sized hydroxyapatite powder by microwave-hydrothermal method. Mater Chem Phys 99: 235- 239

28. Meejoo S, Maneeprakorn W, Winotai P (2006) Phase and thermal stability of nanocrystalline hydroxyapatite prepared via microwave heating. Thermochimica Acta (1): 115-120.

29. Peppas NA (2004) Hydrogels in Biomaterials Science: An Introduction to Materials in Medicine. In: Ratner BD \& Hoffman et al. (Eds.), (2 ${ }^{\text {nd }}$ edn), Academic Press, New York, USA.
30. Boskey A, Pleshko Camacho N (2007) FT-IR imaging of native and tissue-engineered bone and cartilage. Biomaterials 28(15): 24652478.

31. Markovic M, Fowler BO, Tung MS (2004) Preparation and Comprehensive Characterization of a Calcium Hydroxyapatite Reference Material. J Res Natl Inst Stand Technol 109(6): 553-568.

32. Bahrololoom ME, Javidi M, Javadpour S, Ma J (2009) Characterisation of natural hydroxyapatite extracted from bovine cortical bone ash. J Ceram Process Res 10(2): 129-138. 